Supporting Information

\title{
Lithium Titanate Confined in Carbon Nanopores for Asymmetric Supercapacitors
}

Enbo Zhao', Chuanli Qin'2, 3, Hong-Ryun Jung ${ }^{2}$, Gene Berdichevsky ${ }^{4}$, Alper Nese $^{4}$, Seth Marder ${ }^{1,2}$, Gleb Yushin ${ }^{2, *}$ 


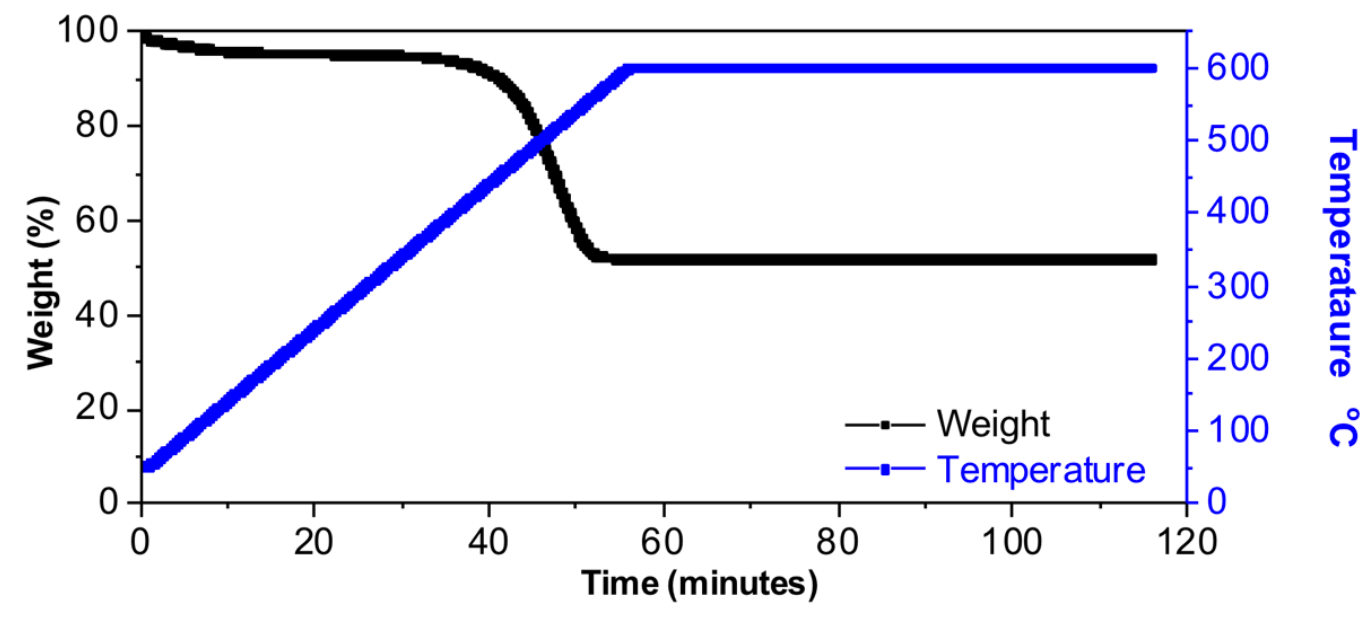

Figure S1. TGA curve of LTO-ACs at $10{ }^{\circ} \mathrm{C} \mathrm{min}{ }^{-1}$ in air.

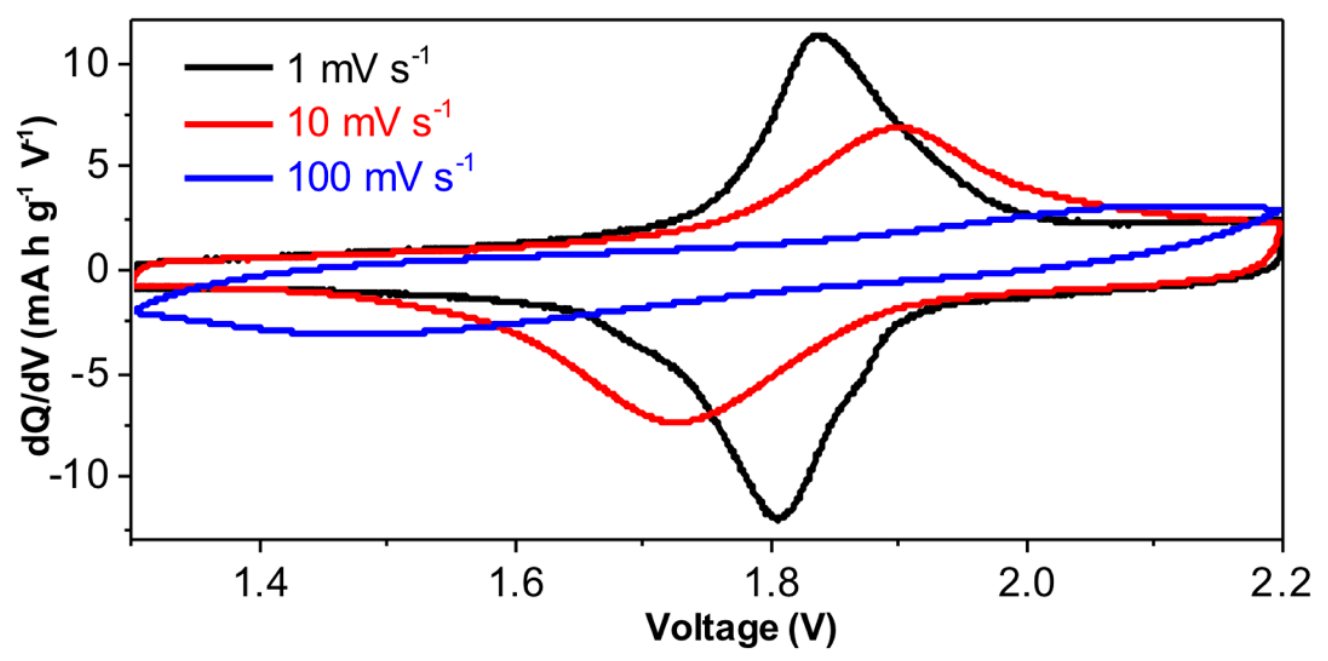

Figure S2. Cyclic voltammetry curves of AC//LTO-ACs full cells. 


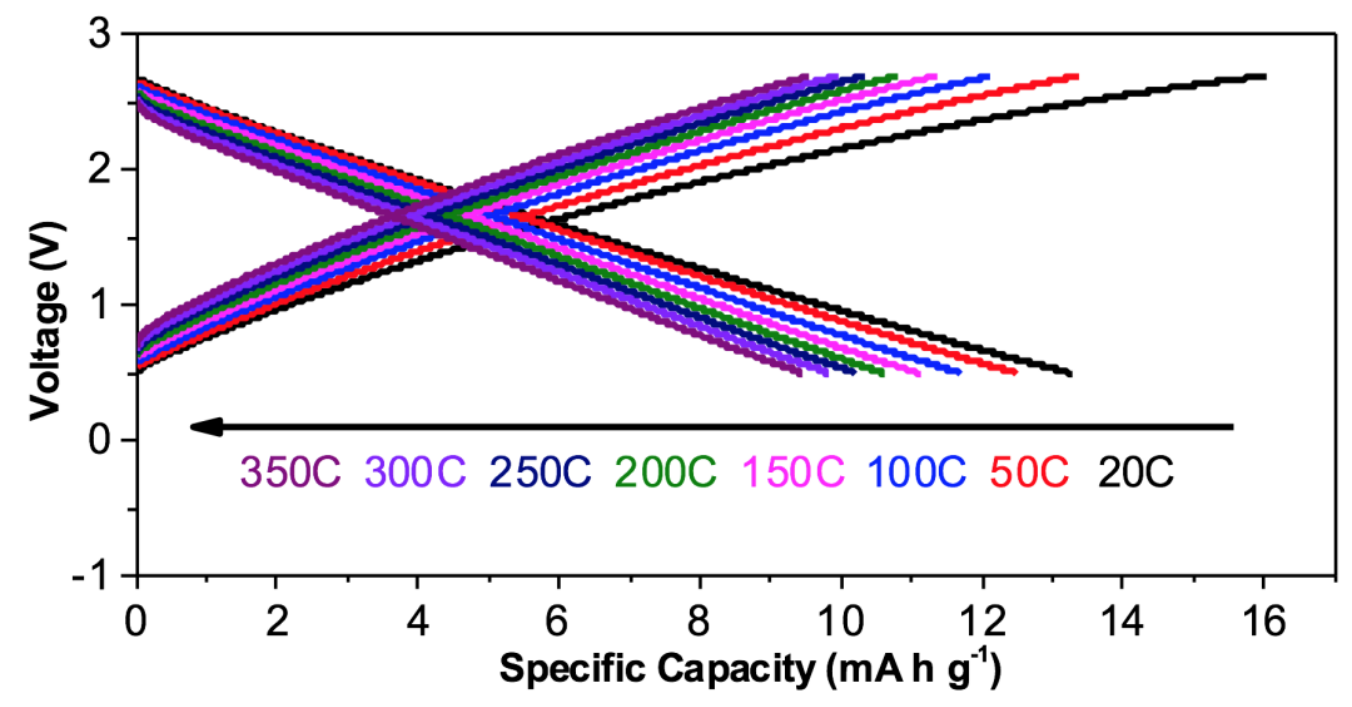

Figure S3. Voltage profiles of AC//AC full cells. Voltage range is $0.5-2.7 \mathrm{~V}$.

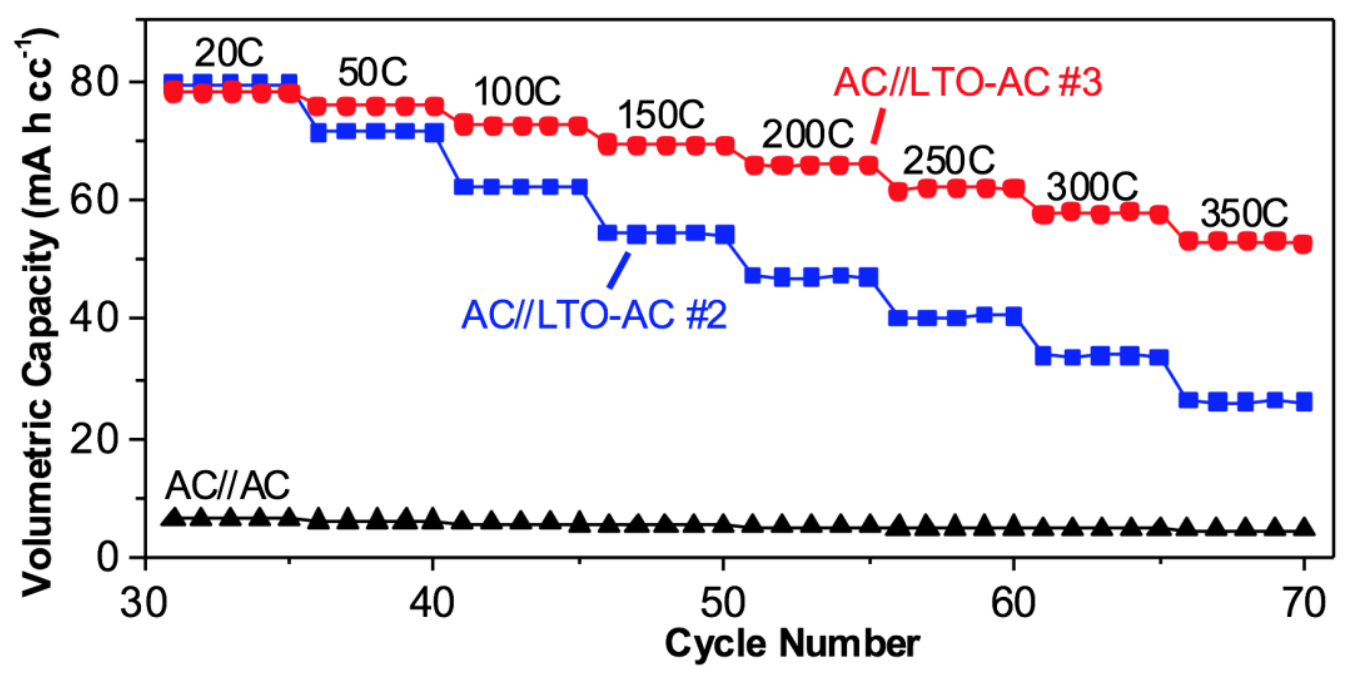

Figure S4. Specific volumetric performances of different AC//LTO-AC full cells in comparison with AC//AC full cell. AC//LTO-ACs are cycled between 1.3-2.2 V while AC//AC is 0.5-2.7 V. 


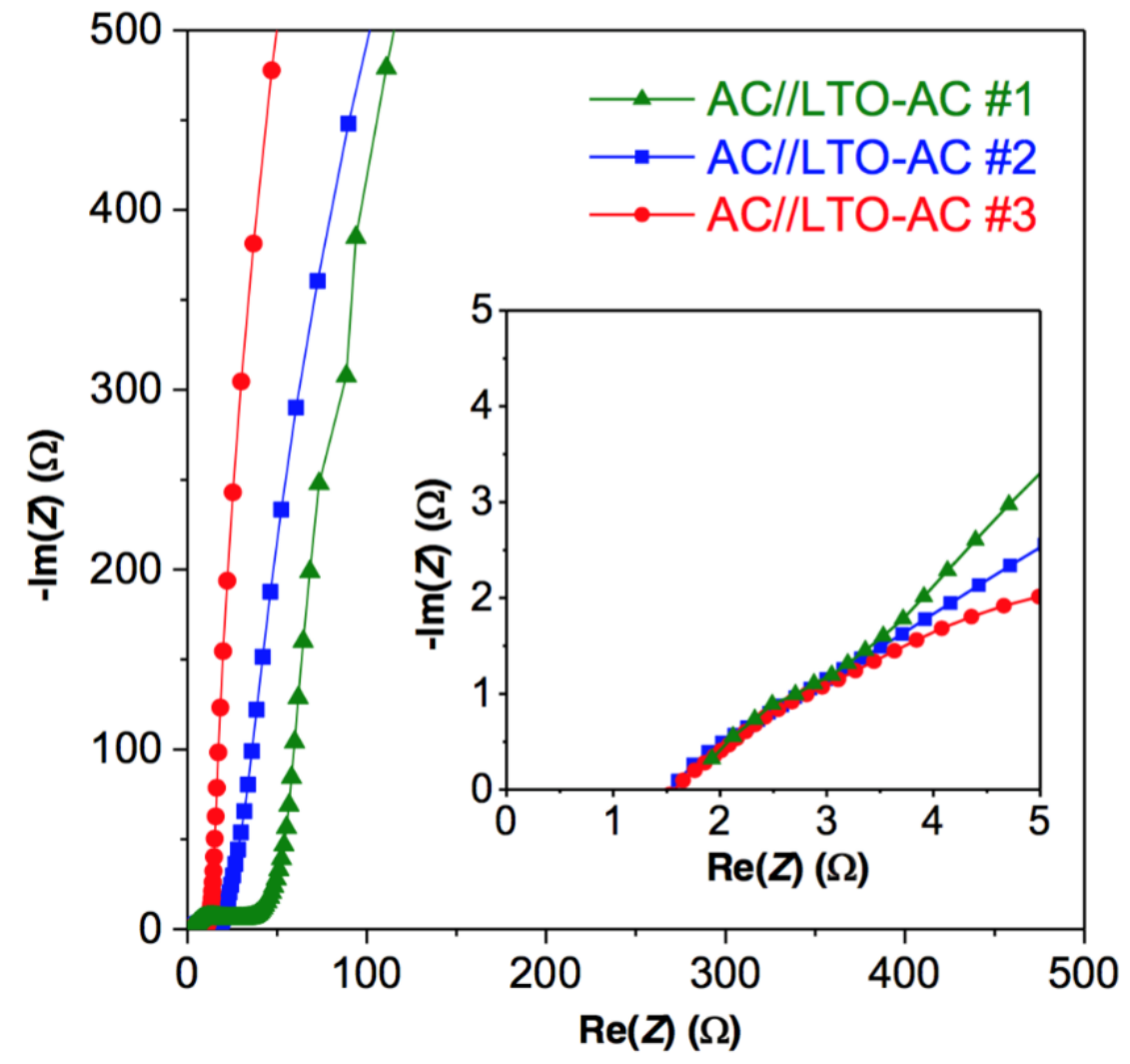

Figure S5. Electrochemical impedance spectroscopy data of the AC//LTO-ACs full cells. The inset shows the magnified high-frequency region. 